\title{
Is Closed-Suction Drainage Essential after Minimally Invasive Lumbar Fusion Surgery?: A Retrospective Review of 381 Cases
}

\author{
Arvind Gopalrao Kulkarni ${ }^{1}$, Ravish Shammi Patel ${ }^{2}$ \\ ${ }^{1}$ Consultant Spine Surgeon, Bombay Hospital and Medical Research Center, \\ ${ }^{2}$ Spine Fellow, Bombay Hospital and Medical Research Center, Mumbai, India
}

Corresponding Author: Arvind Gopalrao Kulkarni, MD, MS, FCPS, SICOT Consultant Spine Surgeon, Mumbai Spine Scoliosis and Disc Replacement Centre, 2nd floor Room No. 206 New Wing, Bombay Hospital \& Medical Research Centre, 12, New Marine Lines, Mumbai- 400020, India

Tel: $+91-9892875490$

Fax: +91-22-22080871

E-mail:

drarvindspines@gmail.com

Received: February 2, 2017 Revised: May 5, 2017 Accepted: May 8, 2017
Objective: Closed suction drains have been widely used after lumbar fusion surgeries but with controversial evidence. The recent advances in the minimally invasive spine surgeries (MIS) lead to smaller dead space, lesser blood loss and fewer infections. With these touted advantages the drains may not be necessary. Our study was aimed to evaluate the outcomes of MIS lumbar fusions without closed-suction drains. Methods: A retrospective review was conducted between June 2007 and January 2016. Patients that underwent MIS transforaminal lumbar interbody fusion (TLIFs) without postoperative drainage were enrolled. Patients with more than 12 months of follow-up were selected. Perioperative variables and clinical outcomes were analysed from the medical records. Incidences of infection and postoperative epidural hematoma were evaluated. Results: Out of 381 patients, there were 341 patients that underwent one-level fusion and 40 patients had two-level fusions. The mean operative time was 218 minutes (range: 150-348 minutes) per level, mean blood loss was $125 \mathrm{~mL}$ per level (range: 80-190 mL) and mean hospital stay was 5 days (range: 4-14 days). Visual Analogue Scale (VAS) leg, VAS back and Oswestry Disability Index (ODI) scores improved by $70.6 \%, 58.6 \%$ and $57.4 \%$ respectively. Three patients had infections and one patient developed postoperative epidural hematoma requiring surgical intervention. The infection rate was $0.78 \%$ and the incidence of postoperative epidural hematoma with the neurological deficit was $0.26 \%$. Conclusion: MIS-TLIFs without a postoperative closed-suction drain showed favourable outcomes. There was no evidence of an increase in the rate of infection or increase in rate of symptomatic postoperative epidural hematoma in patients undergoing MIS-TILFs without a postoperative closed-suction drain.

Key Words: Spine, Lumbar, Arthrodesis, Minimally Invasive Surgical Procedures, Complications, Infections, Epidural hematoma

\section{INTRODUCTION}

Closed suction drains are commonly used in all orthopaedic procedures including spine surgeries ${ }^{24,27)}$. Advantages such as reduction in the rate of epidural hematoma, fewer infections, and lesser post-operative morbidity are claimed to support its use in spine practice. On the contrary, many authors have encountered several disadvantages after using drainage system in spine care. Drains act as an inlet or source of infection; activate local inflammatory response and increase total blood loss ${ }^{2,11)}$. Several meta-analyses had concluded that there is no evidence to support its use in lumbar spine surgeries. In spite of controversial evidence on its utility, drains are being widely used for lumbar fusion surgeries.
Minimally invasive spine surgeries (MIS) have evolved tremendously over last two decades. Lesser blood loss, smaller dead space and fewer infections have been the backbone of the minimally invasive spine surgical techniques ${ }^{7,30)}$. With these advantages, the utility of closed-suction drainage system should reduce considerably. The role of drains after lumbar MIS has not been reviewed conclusively with only a few studies evaluating its role after MIS interbody fusions ${ }^{14)}$. Some centres continue to use drain with these new techniques also. Hence, it is important to review the usefulness of drains after MIS lumbar fusion surgeries.

The present study was aimed to evaluate the outcomes of patients undergoing MIS transforaminal lumbar interbody fusions (TLIFs) without closed suction drainage. The results obtained from our study were extrapolated and compared with the results quoted in the literature. The purpose of the study was to deter- 
mine the usefulness of drains after MIS TLIFs.

\section{MATERIALS AND METHODS}

We retrospectively analysed all patients that underwent MIS TLIFs from June 2007 and January 2016. Patients with less than 12 months of follow-up were excluded. Patients with primary infections, neoplastic aetiology and traumatic injuries bleeding disorders and patients on anticoagulants such as warfarin and low molecular heparins were excluded. As a policy, we did not stop aspirin or clopidogrel for a MIS in patients with a history of stroke or ischemic heart disease. However, the exact number of patients on aspirin or clopidogrel could not be determined from the database. We reviewed medical records for patients' demographic data, diagnosis, existing co-morbid conditions such as hypertension, diabetes, smoking, alcoholism. We obtained the number of levels fused, duration of operation, and length of hospital stay. For evaluating clinical outcomes VAS and ODI scores noted at the end of 12 months were used. All patients were operated by the senior author. We used $22 \mathrm{~mm}$ diameter METRx system (Medtronics, Memphis, TN, USA) aided by a microscope. None of our patients received closed suction drains after their primary surgery. Antibiotics which included 3rd generation cephalosporin and aminoglycoside were continued for 48 hours. Patients were mobilised on the first postoperative day. Patients those who developed dural tears were managed with fibrin glue and water-tight skin closure. Mobilisation in such patients was delayed until the second postoperative day.

For identification of patients with infection, we used Center for Disease Control and Prevention (CDC) classification. Medical records were reviewed for raised biochemical markers and bacteriological analyses. We evaluated patients' records for evidence of wound infection, epidural haematoma, neurological deficit, reoperation, blood loss, transfusion requirements. Postoperative MRI scans were performed on patients who developed postoperative neurological deficit.

\section{RESULTS}

A total of 381 patients underwent MIS-TLIFs with 341 single level fusions and 40 two level fusions (Table 1). The female: male ratio was 1.12:1 with a mean age of $52.3 \pm 11.2$ years (range: 38 to 72 years). We had $27 \%$ patients (103) suffering from diabetes mellitus while we had $36 \%$ patients (137) with hypertension. The mean operative time was $218 \pm 54$ minutes (range: $150-348 \mathrm{mi}-$ nutes) (Table 2). Estimated mean blood loss was $125 \pm 42 \mathrm{~mL}$ (range: $60 \mathrm{~mL}$ to $180 \mathrm{~mL}$ ). The mean hospital stay was $5.1 \pm 1.8$ days (range: $4-14$ days). The mean follow-up was $34.5 \pm 12$ months (range: $12-60$ months). The ODI scores (mean \pm SD) changed from a preoperative score of $45.8 \pm 14.4$ to postoperative score of $19.5 \pm 16.5$ and showed a change of $57.4 \%$. The VAS leg score (mean \pm SD) changed from a preoperative score of $8.5 \pm 1.8$ to postoperative score of $2.5 \pm 2.1$ and showed a change of $70.6 \%$. VAS back pain scores changed from $7.5 \pm 2.3$ to postoperative score of $3.1 \pm 1.8$ and showed a change of $58.6 \%$. Three patients developed a postoperative infection in the early postoperative period. Two patients required thorough wash and debridement. The third patient required unilateral implant removal along with thorough debridement. There were two patients who developed postoperative neurological deficit. On postoperative MRI one of these patients had an epidural hematoma that required revision surgery for hematoma evacuation. The infection rate in our study was $0.78 \%$ and the incidence of postoperative epidural hematoma requiring surgical intervention was $0.26 \%$.

Table 1. Demographic data

\begin{tabular}{|c|c|}
\hline \multicolumn{2}{|l|}{ Patient's demographic data } \\
\hline Age at operation (years) & $\begin{array}{c}52.3 \pm 11.2^{*} \\
\text { (range: } 38-72 \text { ) }\end{array}$ \\
\hline Female:Male & 201:180 \\
\hline $\mathrm{BMl}$ in $\mathrm{kg} / \mathrm{m}^{2}$ & $28.6 \pm 5.6^{*}$ \\
\hline \multicolumn{2}{|l|}{ Occupation } \\
\hline Sedentary & $254(66.7 \%)$ \\
\hline Light work & $110(28.8 \%)$ \\
\hline Heavy manual work & $17(4.5 \%)$ \\
\hline \multicolumn{2}{|l|}{ Fusion levels } \\
\hline One level & $341(89.5 \%)$ \\
\hline Two levels & $40(10.5 \%)$ \\
\hline \multicolumn{2}{|l|}{ Levels fused } \\
\hline L1-L2 & $3(0.7 \%)$ \\
\hline L2-L3 & $10(2.4 \%)$ \\
\hline L3-L4 & $75(17.8 \%)$ \\
\hline L4-L5 & $190(45.1 \%)$ \\
\hline L5-S1 & $143(34 \%)$ \\
\hline \multicolumn{2}{|l|}{ Aetiology } \\
\hline Degenerative Spondylolisthesis & $240(63 \%)$ \\
\hline Spondylolytic Spondylolisthesis & 51 (13.4\%) \\
\hline Degenerative scoliosis & $37(9.7 \%)$ \\
\hline Large disc herniation & $21(5.5 \%)$ \\
\hline Extraforaminal disc herniation & $7(1.8 \%)$ \\
\hline Failed back syndrome (revision) & $25(6.6 \%)$ \\
\hline \multicolumn{2}{|l|}{ Patients with co-morbidities } \\
\hline Diabetes Mellitus & $103(27 \%)$ \\
\hline Smoking & $62(16 \%)$ \\
\hline Alcohol consumption & $70(18 \%)$ \\
\hline Osteoporosis & $152(40 \%)$ \\
\hline Hypertension & $137(36 \%)$ \\
\hline Use of anti-coagulants & $42(11 \%)$ \\
\hline Use of anti-depressants & $10(2.6 \%)$ \\
\hline \multicolumn{2}{|l|}{ Disability scores (meanะSD) } \\
\hline VAS $^{\text {leg }}$ & $8.5 \pm 1.8^{*}$ \\
\hline VAS ${ }^{\text {back }}$ & $7.5 \pm 2.3^{*}$ \\
\hline ODI & $45.8 \pm 14.4^{*}$ \\
\hline
\end{tabular}

*Values expressed as mean \pm standard deviation (SD). 
Table 2. Perioperative variables

\begin{tabular}{|c|c|}
\hline Perioperative data & \\
\hline Duration of Surgery (minutes) & $\begin{array}{c}218 \pm 54^{*} \\
\text { (range: } 150-348 \text { ) }\end{array}$ \\
\hline Intraoperative blood loss & $\begin{array}{l}125 \pm 42^{*} \\
\text { (range: } 60-180)\end{array}$ \\
\hline Patients with dural tears & $10(2.6 \%)$ \\
\hline $\begin{array}{l}\text { Patients with postoperative neurological } \\
\text { deficit }\end{array}$ & $2(0.5 \%)$ \\
\hline Patients with postoperative hematoma & $1(0.26 \%)$ \\
\hline Patients with postoperative infection & $3(0.78 \%)$ \\
\hline Mean Hospital Stay (days) & $\begin{array}{c}5.1 \pm 1.8^{*} \\
\text { (range: } 4-14)\end{array}$ \\
\hline Postoperative VAS ${ }^{\text {leg }}$ score & $2.5 \pm 2.1^{*}$ \\
\hline Change in VAS ${ }^{\text {leg }}$ score & $70.6 \%$ \\
\hline Postoperative VAS ${ }^{\text {back }}$ score & $3.1 \pm 1.8^{*}$ \\
\hline Change in VAS ${ }^{\text {back }}$ score & $58.6 \%$ \\
\hline Postoperative ODI score & $19.5 \pm 16.5^{*}$ \\
\hline Change in ODI score & $57.4 \%$ \\
\hline
\end{tabular}

*Values expressed as mean \pm standard deviation (SD).

\section{DISCUSSION}

The decision whether to use or not to use a drain tube is usually made by the operating surgeon. The choice is generally based on surgeon's satisfaction on the quality of hemostasis achieved, the magnitude of the surgical procedure and the risk of bleeding. In a recent study conducted by Kajetan et al., surgeons have heterogeneous opinions in terms of indication, duration and safety measures related to drain use $^{28)}$. In his study, 69\% doctors preferred to use drains after instrumented surgeries. The decision to use or not to use drain was subjective and there was no clear conscience for its use.

The postoperative epidural hematoma was observed in $0.26 \%$ of our patients. Usually, drains are used to reduce the incidence of postoperative hematoma and risk of wound infection. The incidence of the symptomatic epidural hematoma is $0.1-0.24 \%$ while that of asymptomatic epidural hematoma is $86 \%$ on the first postoperative day ${ }^{1,15,17)}$. It has been argued that drain reduces the incidence of the postoperative hematoma and also reduces the postoperative fibrosis ${ }^{21,26)}$. But as the occurrence of symptomatic postoperative hematoma is very rare, there may not be any clinically noticeable advantage of the suction drains. Also, large studies that were sensitive enough to detect statistically significant difference in the incidences of epidural hematoma had observed that there was no added benefit of using drains after lumbar spinal surgery. Awad et al. in his study of over 14,932 patients observed that 32 patients suffered from a symptomatic epidural haematoma $(0.21 \%)$ and its incidence was not influenced by drain usage ${ }^{1)}$. Similarly, Kou et al. observed that 12 out of 12,000 patients developed an epidural hematoma
$(0.1 \%)$ and concluded that there was no protective effect of subfascial drains in his retrospective case series ${ }^{17)}$. Hence, it can be inferred that there is insufficient evidence to suggest the prophylactic use of drains against epidural hematoma ${ }^{19}$.

Similarly, there is no role of drains in reducing overall wound complication and wound healing. The overall infection rate in our study was $0.78 \%$. In a recent meta-analysis, Glennie et al. observed that deep surgical wound drains did not affect wound healing in posterior spine surgery ${ }^{11)}$. Kanayama et al. and Brown et al. did not observe any infection with or without drains3, 15). Walid et al. reviewed 402 patients undergoing lumbar fusion with decompression and observed 3.5\% infection rate with drains and $2.6 \%$ without drains ${ }^{29)}$. The difference was however statistically insignificant. Similarly, Payne et al. evaluated wound healing in a prospective randomised study of 205 patients undergoing single-level non-fusion lumbar surgery and obtained 1.9\% infection with drains and $1.0 \%$ without drains ${ }^{25}$. In the meta-analysis done by Liu et al., the infection rate in drainage group was $1.6 \%$ and $0.7 \%$ in the nondrainage group respectively after lumbar fusion surgeries ${ }^{19)}$. None of the above studies obtained a statistically significant difference in the infection and wound complication rates with or without drains. Hence it can be safely concluded that drains did not reduce the incidence of surgical site infections.

There are many disadvantages of using closed suction drain. Transfusion requirement of patients increases after usage of closed suction drain ${ }^{3)}$. Walid et al. analysed 402 patients undergoing lumbar fusions and concluded that drain increases posthemorrhagic anaemia (23.5 vs. $7.7 \%$ ) and allogenic blood transfusion (23.9\% vs. 6.8\%)29). He also observed that closed-suction drain usage was associated with longer hospital stay and increased prevalence of postoperative infection ${ }^{29)}$. Increased blood product transfusion has been observed after adolescent idiopathic scoliosis surgery (43\% vs. 22\%), revision hip arthroplasty (44\% vs. $20 \%)$ and minimally invasive knee arthroplasty (41\% vs. $28.5 \%)^{5,9,31)}$. On the contrary, none of our patients required blood transfusion in the postoperative period. The total blood loss never exceeded $200 \mathrm{~mL}$ in our study. Also, the insertion of surgical drain requires additional time, effort and perioperative care. Surgeons fear that drains may act as an inlet or porter of infection ${ }^{11,14)}$. It can also expose epidural space to external pathogens. Drains are a source of discomfort to patients and considerably delay active early mobilisation after lumbar fusion surgeries ${ }^{14)}$. Hence avoiding a drain would provide a fewer postoperative transfusions, rapid recovery, and reduced peri-operative morbidity as observed in our study.

Minimally invasive surgeries have certain touted advantages due to which the effectiveness of closed suction drains can reduce further. MIS-TLIF involves minimal soft tissue damage and the midline soft tissue collar is left untouched ${ }^{8,13)}$. After removal of the tubular retractors, the elastic recoil of the paraspinal muscles leaves a much smaller dead space at the local site than the dead space left after open surgery ${ }^{12)}$. Hence minimal space is available for collection, pooling of blood and to form a spinal hematoma. As the tissue destruction is minimal, the amount of intraoperative blood loss and tissue necrosis are 
also very less ${ }^{78)}$. We believe that better haemostasis can be achieved with MIS as they are performed under an operating microscope. A meticulous bleeding control can be achieved with cauterisation of epidural bleeding points under the magnified vision of an operating microscope. Hence as observed in our study, the incidence of epidural hematoma did not increase compared to the rates quoted in the literature. Also, the incidence of infection reported after minimally invasive fusion surgeries is less and varies from $0.09 \%$ to $2.5 \%{ }^{7,8,20)}$. The infection rate $(0.78 \%)$ observed in our study is coherent with previously reported studies.

We included patients with a minimal follow-up of 12 months so as to include most of the patients encountering infection after lumbar fusion surgery ${ }^{18)}$. It was critical to note that in our study there were $27 \%$ patients with diabetes mellitus and $36 \%$ patients with hypertension. Few other studies have shown similar results corresponding to our observations. Hung et al. conducted prospective randomised control trial to evaluate the utility of drain usage and found that drains are not necessary after MIS-TLIF ${ }^{14}$. He found that patients without drain had the benefit of earlier ambulation than those with drains. Eckman et al. reported same-day discharge in 808 patients out of 1,114 patients and all of them undergoing MIS-TLIFs without postoperative surgical drains ${ }^{6}$. Hence it can be concluded that drains could be safely avoided after MIS-TLIFs.

Many of our patients were on aspirin or clopidogrel in the perioperative period. No attempt was made to stop these drugs in the perioperative period. Jackson et al. did a prospective study of comparison of 100 patients that were on aspirin with 100 patients in whom aspirin was stopped in the perioperative period $^{4)}$. He observed that there was no increase in bleeding related complications in patients undergoing spine surgery while continuing aspirin compared to patients in whom aspirin was stopped. A similar prospective randomized clinical trial was conducted by Oscarrson et al. on 220 patients undergoing non-cardiac surgery ${ }^{22)}$. He concluded that patients that were allowed to continue aspirin in the perioperative period had reduced risk of major cardiac adverse events without increasing the bleeding related complications. While Kang and Park et al. showed that continuing aspirin in the perioperative period increases the postoperative drainage ${ }^{16,23)}$. However there was no increase in the rate of spinal hematoma. Patient specific strategy is needed for perioperative aspirin management that weighs the risk of stopping aspirin with those associated with its continuation ${ }^{10)}$. Authors are of the opinion that if meticulous hemostasis is achieved, drains can be avoided in patients with aspirin/clopidogrel. We do not have any experience of MIS in patients of bleeding tendencies or patients on perioperative warfarin/low molecular weight heparin.

Our study was a retrospective case series reporting the outcomes of MIS-TLIF without a closed suction drain. A prospective randomised case-control study with a control group would have provided more conclusive evidence. However, as evident from our study, the rate of hematoma and infection does not increase after MIS-fusion surgery.

\section{CONCLUSION}

The necessity of closed-suction drain after MIS lumbar fusion is questionable. The effectiveness of closed-suction drainage system would reduce further due to the touted advantages of MIS technique. MIS-TLIFs without a postoperative closed-suction drain showed favourable outcomes. There was no evidence of increase in the rate of infection or increase in rate of symptomatic postoperative epidural hematoma in patients undergoing MISTILFs without a postoperative closed-suction drain.

\section{REFERENCES}

1. Awad JN, Kebaish KM, Donigan J, Cohen DB, Kostuik JP: Analysis of the risk factors for the development of post-operative spinal epidural haematoma. J Bone Joint Surg Br 87:1248-1252, 2005

2. Bachoura A, Guitton TG, Smith RM, Vrahas MS, Zurakowski D, Ring D: Infirmity and injury complexity are risk factors for surgical-site infection after operative fracture care. Clin Orthop Relat Res 469:2621-2630, 2011

3. Brown MD, Brookfield KF: A randomized study of closed wound suction drainage for extensive lumbar spine surgery. Spine (Phila Pa 1976) 29:1066-1068, 2004

4. Cuellar JM, Petrizzo A, Vaswani R, Goldstein JA, Bendo JA: Does aspirin administration increase perioperative morbidity in patients with cardiac stents undergoing spinal surgery? Spine (Phila Pa 1976) 40:629-635, 2015

5. Diab M, Smucny M, Dormans JP, Erickson MA, Ibrahim K, Lenke LG, et al: Use and Outcomes of Wound Drain in Spinal Fusion for Adolescent Idiopathic Scoliosis. Spine 37:966-973, 2012

6. Eckman WW, Hester L, McMillen M: Same-day Discharge After Minimally Invasive Transforaminal Lumbar Interbody Fusion: A Series of 808 Cases. Clinical Orthopaedics and Related Research 472:1806-1812, 2014

7. Ee WWG, Lau WLJ, Yeo W, Bing YV, Yue WM: Does Minimall y Invasive Surgery Have a Lower Risk of Surgical Site Infections Compared With Open Spinal Surgery? Clinical Orthopaedics and Related Research 472:1718-1724, 2014

8. Fessler RG, O'Toole JE, Eichholz KM, Perez-Cruet MJ: The development of minimally invasive spine surgery. Neurosurg Clin N Am 17:401-409, 2006

9. Fichman SG, Makinen TJ, Lozano B, Rahman WA, Safir O, Gross $\mathrm{AE}$, et al: Closed suction drainage has no benefits in revision total hip arthroplasty: a randomized controlled trial. Int Orthop 40:453-457, 2016

10. Gerstein NS, Schulman PM, Gerstein WH, Petersen TR, Tawil I: Should more patients continue aspirin therapy perioperatively? : clinical impact of aspirin withdrawal syndrome. Ann Surg 255: 811-819, 2012

11. Glennie RA, Dea N, Street JT: Dressings and drains in posterior spine surgery and their effect on wound complications. Journal of Clinical Neuroscience 22:1081-1087, 2015

12. Goldstein CL, Macwan K, Sundararajan K, Rampersaud YR: Comparative Outcomes of Minimally Invasive Surgery for Poste- 
rior Lumbar Fusion: A Systematic Review. Clinical Orthopaedics and Related Research 472:1727-1737, 2014

13. Guan J, Bisson EF, Dailey AT, Hood RS, Schmidt MH: Comparison of Clinical Outcomes in the National Neurosurgery Quality and Outcomes Database for Open Versus Minimally Invasive Transforaminal Lumbar Interbody Fusion. Spine 41: E416-E421, 2016

14. Hung PI, Chang MC, Chou PH, Lin HH, Wang ST, Liu CL: Is a drain tube necessary for minimally invasive lumbar spine fusion surgery? Eur Spine J 2016

15. Kanayama M, Oha F, Togawa D, Shigenobu K, Hashimoto T: Is Closed-suction Drainage Necessary for Single-level Lumbar Decompression?: Review of 560 Cases. Clinical Orthopaedics and Related Research 468:2690-2694, 2010

16. Kang SB, Cho KJ, Moon KH, Jung JH, Jung SJ: Does low-dose aspirin increase blood loss after spinal fusion surgery? Spine J 11:303-307, 2011

17. Kou J, Fischgrund J, Biddinger A, Herkowitz H: Risk factors for spinal epidural hematoma after spinal surgery. Spine (Phila Pa 1976) 27:1670-1673, 2002

18. Lee JS, Ahn DK, Chang BK, Lee JI: Treatment of Surgical Site Infection in Posterior Lumbar Interbody Fusion. Asian Spine J 9:841-848, 2015

19. Liu JM, Chen WZ, Fu BQ Chen JW, Liu ZL, Huang SH: The Use of Closed Suction Drainage in Lumbar Spinal Surgery: Is It Really Necessary? World Neurosurgery 90:109-115, 2016

20. McGirt MJ, Parker SL, Lerner J, Engelhart L, Knight T, Wang MY: Comparative analysis of perioperative surgical site infection after minimally invasive versus open posterior/transforaminal lumbar interbody fusion: analysis of hospital billing and discharge data from 5,170 patients Clinical article. Journal of Neurosurgery-Spine 14:771-778, 2011

21. Mirzai H, Eminoglu M, Orguc S: Are drains useful for lumbar disc surgery? A prospective, randomized clinical study. J Spinal Disord Tech 19:171-177, 2006

22. Oscarsson A, Gupta A, Fredrikson M, Jarhult J, Nystrom M, Pettersson E, et al: To continue or discontinue aspirin in the perioperative period: a randomized, controlled clinical trial. $\mathrm{Br}$ J Anaesth 104:305-312, 2010
23. Park JH, Ahn Y, Choi BS, Choi KT, Lee K, Kim SH, et al: Antithrombotic effects of aspirin on 1- or 2-level lumbar spinal fusion surgery: a comparison between 2 groups discontinuing aspirin use before and after 7 days prior to surgery. Spine (Phila Pa 1976) 38:1561-1565, 2013

24. Parker MJ, Livingstone V, Clifton R, McKee A: Closed suction surgical wound drainage after orthopaedic surgery. Cochrane Database Syst Rev: CD001825, 2007

25. Payne DH, Fischgrund JS, Herkowitz HN, Barry RL, Kurz LT, Montgomery DM: Efficacy of closed wound suction drainage after single-level lumbar laminectomy. J Spinal Disord 9:401403, 1996

26. Sen O, Kizilkilic O, Aydin MV, Yalcin O, Erdogan B, Cekinmez $\mathrm{M}$, et al: The role of closed-suction drainage in preventing epidural fibrosis and its correlation with a new grading system of epidural fibrosis on the basis of MRI. Eur Spine J 14:409-414, 2005

27. Takemoto RC, Lonner B, Andres T, Park J, Ricart-Hoffiz P, Bendo J, et al: Appropriateness of Twenty-four-Hour Antibiotic Prophylaxis After Spinal Surgery in Which a Drain Is Utilized: A Prospective Randomized Study. J Bone Joint Surg Am 97: 979-986, 2015

28. von Eckardstein KL, Dohmes JE, Rohde V: Use of closed suction devices and other drains in spinal surgery: results of an online, Germany-wide questionnaire. European Spine Journal 25:708715, 2016

29. Walid MS, Abbara M, Tolaymat A, Davis JR, Waits KD, Robinson JS, 3rd, et al: The role of drains in lumbar spine fusion. World Neurosurg 77:564-568, 2012

30. Wang MY, Lerner J, Lesko J, McGirt MJ: Acute hospital costs after minimally invasive versus open lumbar interbody fusion: data from a US national database with 6106 patients. J Spinal Disord Tech 25:324-328, 2012

31. Zhang QD, Zhang Q, Guo WS, Liu ZH, Cheng LM, Zhu GD: No need for use of drainage after minimally invasive unicompartmental knee arthroplasty: a prospective randomized, controlled trial. Archives of Orthopaedic and Trauma Surgery 135: 709-713, 2015 